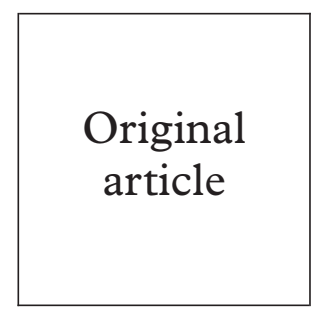

\title{
Trichomonas vaginalis epidemiology: parameterising and analysing a model of treatment interventions
}

\author{
Francis J Bowden, Geoffrey P Garnett
}

Background: Trichomonas vaginalis, which affects at least 170 million individuals globally, may increase the risk of transmission of HIV and predispose pregnant women to premature rupture of membranes and early labour.

Objective: To more clearly define the epidemiology of trichomoniasis and to develop a mathematical model of disease transmission dynamics in order to explore various treatment strategies.

Design: A deterministic model of trichomoniasis was constructed. Parameter values were set to fit the model to known endemic prevalence levels of Trichomonas vaginalis. Two treatment interventions ("screening" and "syndromic management") were simulated.

Results: The age specific prevalence of the disease was seen to differ from other STDs in a number of studies. Parameter fitting indicates that the average duration of infection in women is at least 3-5 years and approximately 4 months for men. "Syndromic management" (that is, treating only those with symptoms of disease) had minimal effect upon the endemic prevalence of disease even at high levels of coverage. "Screening" (that is, identification of individuals with both symptomatic and asymptomatic infection) was shown to be the most efficient method of control, but was sensitive to the screening interval.

Conclusions: The control of trichomoniasis seems to have been a success in developed countries because of the regular access to health care, whereas it has remained endemic in many developing countries where control may only be possible by regular screening and treatment. However, without a large investment in services, success in controlling trichomoniasis is likely to be transitory.

(Sex Transm Inf 2000;76:248-256)

Keywords: HIV; trichomoniasis; Trichomonas vaginalis; mathematical modelling; screening; syndromic management

\section{Introduction}

Trichomonas vaginalis is one of the commonest sexually transmitted pathogens in the world, with an estimated 170 million cases occurring each year. ${ }^{1}$ The epidemiology of the disease is still poorly understood and some practitioners continue to question its importance. However, there is growing evidence that $T$ vaginalis is an important pathogen, both in its own right due to the "immediate" morbidity associated with infection, ${ }^{2}$ for its role in the promotion of premature rupture of membranes, premature labour, and low birth weight, ${ }^{34}$ and because of the likely facilitation of HIV transmission..$^{5-7}$ While a slightly increased risk for HIV transmission may have minor significance for an individual, it may be of considerable importance at a community level. ${ }^{8}$ Understanding the relation between $T$ vaginalis and other sexually transmitted infections would assist its use as a marker for the success of behavioural and treatment interventions targeting other STDs including HIV.

In this paper we review the transmission dynamics of $T$ vaginalis infection in the context of a mathematical model of the infection. Parameters needed for the development of this model were estimated from a review of the relevant, largely historical, literature. The review illustrates the difficulties found in describing the epidemiology of a treatable, frequently asymptomatic infection, which probably contributes to the scant attention devoted to this organism. We present some of the insights gained from analysis of this model, which have implications for the design of public health programmes for the control of STDs, with particular relevance to developing countries.

\section{Prevalence studies}

The prevalence of $T$ vaginalis varies markedly according to the setting (table 1). ${ }^{4-37}$ The estimates presented in the table are subject to important biases: the diagnostic methods employed are not consistent and, with only three exceptions, ${ }^{14} 3738$ the data are drawn from clinic based surveys. Although there is anecdotal evidence that $T$ vaginalis prevalence is low in women in higher socioeconomic groups, the published studies show that the prevalence may be as high as $50 \%$ in women in the developing world and in minority groups in industrialised populations. Similarly, the prevalence in men in developed countries appears to be low but there are only limited data in men in developing populations. A study in Papua New Guinea showed that the male indigenous population had a prevalence of $10.9 \%$ compared with a prevalence of $0 \%$ in the male white population. ${ }^{16}$ Only four studies have 
Table 1 Estimates of the prevalence of $T$ vaginalis infection and proportion with symptoms

\begin{tabular}{|c|c|c|c|c|c|c|c|}
\hline \multirow[b]{2}{*}{ Study } & \multirow[b]{2}{*}{ Year } & \multirow[b]{2}{*}{ Setting } & \multirow[b]{2}{*}{ Diagnostic method } & \multicolumn{2}{|l|}{ Prevalence } & \multicolumn{2}{|l|}{ Symptoms } \\
\hline & & & & Male & Female & Male & Female \\
\hline Drummond $^{47}$ & 1936 & $\begin{array}{l}\text { US, contacts of infected } \\
\text { women }\end{array}$ & Microscopy and culture & - & - & $0 / 4(0 \%)$ & \\
\hline Peterson $^{9}$ & 1938 & $\begin{array}{l}\text { US, O\&G clinic naval } \\
\text { hospital }\end{array}$ & Microscopy & - & $24.6 \%$ & - & $\begin{array}{l}606 / 1405 \\
(36 \%)\end{array}$ \\
\hline $\mathrm{Feo}^{10}$ & 1943 & US, army recruits & $\begin{array}{l}\text { Microscopy of urethral } \\
\text { swabs }\end{array}$ & $\begin{array}{l}16.6 \% \text { (blacks); } \\
12.0 \% \text { (whites) }\end{array}$ & - & - & $13 / 24(54.2 \%)$ \\
\hline Whittington $^{11}$ & 1951 & UK, birth control clinic & Culture & - & $5.3 \%$ & $1 / 7(14.3 \%)$ & - \\
\hline Coutts et al. ${ }^{12}$ & 1955 & Chile, men with NGU & Microscopy & $68 \%$ & - & - & - \\
\hline Whitington $^{45}$ & 1957 & $\begin{array}{l}\text { UK, contacts of infected } \\
\text { women }\end{array}$ & Microscopy and culture & - & - & $51 / 63(80 \%)$ & - \\
\hline Buxton et al. ${ }^{13}$ & 1958 & $\begin{array}{l}\text { US, "well workers", O\&G } \\
\text { clinic, mental institution, } \\
\text { women's college }\end{array}$ & Culture & - & $\begin{array}{l}6.3 \% \text { (married workers); } \\
6.9 \% \text { (clinic); } \\
15 \% \text { (mental institution); } \\
0 \% \text { (undergraduates). }\end{array}$ & - & - \\
\hline Burch $e t a l^{14}$ & 1959 & US, vaginal cytology survey & Culture & - & $\begin{array}{l}60.9 \% \text { (blacks) } \\
8.1 \% \text { (whites) }\end{array}$ & - & - \\
\hline Weston and Nicol ${ }^{55}$ & 1963 & $\begin{array}{l}\text { UK, contacts of infected } \\
\text { women }\end{array}$ & Microscopy and culture & $45.1 \%$ & - & $\begin{array}{l}54 / 68 \\
(79.4 \%)\end{array}$ & - \\
\hline Wisdom and Dunlop ${ }^{15}$ & 1965 & UK, STD clinic attenders & Unspecified & $\begin{array}{l}5.6 \%(\mathrm{NGU} \\
\text { patients) }\end{array}$ & $31.5 \%$ & $\begin{array}{l}5 / 13 \\
(39.5 \%)\end{array}$ & $\begin{array}{l}337 / 513 \\
(71.7 \%)\end{array}$ \\
\hline \multirow[t]{2}{*}{ Ipsen and Feigl ${ }^{39}$} & \multirow[t]{2}{*}{1970} & \multirow{2}{*}{$\begin{array}{l}\text { US, } 38000 \text { "healthy } \\
\text { workers" screened in } \\
\text { Philadelphia }\end{array}$} & \multirow[t]{2}{*}{ Pap smear } & \multirow[t]{2}{*}{ - } & $30.4 \%$ (blacks) & \multirow[t]{2}{*}{ - } & \multirow[t]{2}{*}{ - } \\
\hline & & & & & $10.7 \%$ (whites) & & \\
\hline \multirow[t]{2}{*}{ Zigas $^{16}$} & \multirow[t]{2}{*}{1977} & \multirow{2}{*}{$\begin{array}{l}\text { PNG, health clinic, STD } \\
\text { clinic attenders and male } \\
\text { prisoners }\end{array}$} & \multirow[t]{2}{*}{ Microscopy } & $10.9 \%$ (melanesian) & $44.6 \%$ (melanesian); & \multirow[t]{2}{*}{-} & \multirow[t]{2}{*}{-} \\
\hline & & & & $0 \%$ (white) & $14.2 \%$ (white). & & \\
\hline Tapsall et al. ${ }^{17}$ & 1979 & $\begin{array}{l}\text { Australia, antenatal and } \\
\text { STD clinics }\end{array}$ & Microscopy and culture & - & $\begin{array}{l}0.5 \% \text { (antenates); } \\
17.8 \% \text { (STD clinics). }\end{array}$ & - & - \\
\hline Wilson and Ackers ${ }^{18}$ & 1980 & UK, STD clinic & Urine culture & $\begin{array}{l}14 \% \text { (contacts of } \\
\text { women with } T \\
\text { vaginalis) } \\
0 \% \text { (other clinic } \\
\text { attenders) }\end{array}$ & - & - & - \\
\hline Mirza et al ${ }^{19}$ & 1983 & Nairobi, STD clinics & Microscopy & - & $34 \%$ & - & - \\
\hline Hardy et $a l^{20}$ & 1984 & US, antenatal clinic & Culture & - & $34 \%$ & - & - \\
\hline Mabey et $a l^{11}$ & 1984 & $\begin{array}{l}\text { The Gambia, antenatal } \\
\text { clinic }\end{array}$ & Microscopy and culture & - & $32 \%$ & - & - \\
\hline Wolner-Hanssen et al ${ }^{22}$ & 1989 & US, STD clinic & Microscopy and culture & - & $15 \%$ & - & - \\
\hline O'Farrell et a ${ }^{3}$ & 1989 & $\begin{array}{l}\text { South Africa, rural } \\
\text { antenatal clinics }\end{array}$ & Microscopy and culture & - & $49.2 \%$ & - & - \\
\hline Lefevre et $a l^{4}$ & 1991 & France, men with urethritis & Microscopy and culture & $1.8 \%$ & - & - & - \\
\hline Saxena and Jenkins ${ }^{25}$ & 1991 & $\begin{array}{l}\text { US, men at high risk for } \\
\text { STDs }\end{array}$ & $\begin{array}{l}\text { Urine and urethral } \\
\text { culture and microscopy }\end{array}$ & $58 \%$ & - & $24 / 49(49 \%)$ & - \\
\hline Iyer et $a l^{26}$ & 1991 & India, STD clinic & Microscopy & $15.8 \%$ & - & - & - \\
\hline Stefanik et $a l^{7}$ & 1992 & $\begin{array}{l}\text { Czechoslovakia, military } \\
\text { personnel with urethritis }\end{array}$ & Culture & 0.7 & - & - & - \\
\hline Krieger et a $2^{8}$ & 1992 & US, STD clinic & $\begin{array}{l}\text { Urethral and urine } \\
\text { culture }\end{array}$ & $11 \%$ & - & $27 / 50(54 \%)$ & - \\
\hline Anosike et $a l^{29}$ & 1993 & Nigeria, university students & Urine culture & $15.6 \%$ & $31 \%$ & - & - \\
\hline DeHovitz et al $l^{66}$ & 1994 & $\begin{array}{l}\text { US, inner city women } \\
\text { recruited for health checks }\end{array}$ & Culture & - & $28.7 \%$ & - & - \\
\hline Cronje et $a l^{30}$ & 1994 & $\begin{array}{l}\text { South Africa, random } \\
\text { community sample }\end{array}$ & Microscopy & - & $\begin{array}{l}27.4 \% \text { (rural); } \\
29.6 \% \text { (urban). }\end{array}$ & - & - \\
\hline Borchardt $e t a l^{11}$ & 1995 & STD clinic & $\begin{array}{l}\text { Urine microscopy and } \\
\text { culture }\end{array}$ & $12 \%$ & - & - & - \\
\hline Tabrizi et $a l^{32}$ & 1996 & $\begin{array}{l}\text { Australia, rural and remote } \\
\text { health clinics }\end{array}$ & $\begin{array}{l}\text { PCR of tampon } \\
\text { specimens }\end{array}$ & - & $25 \%$ & - & - \\
\hline Heine $e t a l^{\beta}$ & 1997 & US, STD clinic & PCR & - & $46 \%$ & - & - \\
\hline Klouman et $a b^{44}$ & 1997 & $\begin{array}{l}\text { Tanzania, rural community } \\
\text { survey }\end{array}$ & Microscopy & - & $24.7 \%$ & - & - \\
\hline Cotch et al ${ }^{4}$ & 1997 & US, antenatal clinics & Culture & - & $\begin{array}{l}22.8 \% \text { (black); } \\
6.6 \% \text { (hispanic); } \\
6.1 \% \text { (white). }\end{array}$ & - & - \\
\hline Waghorn et $a l^{35}$ & 1998 & $\begin{array}{l}\text { UK, cervical smear } \\
\text { specimens }\end{array}$ & Microscopy & - & $0.1 \%$ & - & - \\
\hline El Seoud et a $\beta^{6}$ & 1998 & Egypt, STD clinic & $\begin{array}{l}\text { Urine and urethral } \\
\text { microscopy and culture }\end{array}$ & $\begin{array}{l}8.2 \% \text { (impotence } \\
\text { and infertility) } \\
28.8 \% \text { (urethral } \\
\text { discharge) }\end{array}$ & - & - & - \\
\hline Sorvillo et a $l^{67}$ & 1998 & $\begin{array}{l}\text { US, women attending } \\
\text { public HIV clinic }\end{array}$ & $\begin{array}{l}\text { Microscopy or Pap } \\
\text { smear }\end{array}$ & - & $\begin{array}{l}6.6 \% \text { (white); } \\
37.5 \% \text { (black); } \\
10.5 \% \text { (latino). }\end{array}$ & - & - \\
\hline Passey et $a B^{77}$ & 1998 & $\begin{array}{l}\text { PNG, community based } \\
\text { random clusters }\end{array}$ & Microscopy & - & $46 \%$ & - & - \\
\hline Madico et $a \bar{l}^{0}$ & 1998 & US, army STD clinic & PCR of vaginal swabs & - & $9.4 \%$ & - & - \\
\hline
\end{tabular}

determined the age specific prevalence of $T$ vaginalis infection. ${ }^{14} 163839$ In each the prevalence was shown to increase monotonically with age among women, a feature not seen in short duration, bacterial STDs, representing a fundamental difference in the epidemiology of this pathogen.

\section{Description of the model}

We adopted a deterministic model which was originally developed for Neisseria gonorrhoeae infection. ${ }^{40}{ }^{41}$ This model simplifies the natural history of $T$ vaginalis infection by dividing the population at risk into three disease states (i) those susceptible to $T$ vaginalis infection $(\mathrm{X})$; 
(ii) those with symptomatic infection $(\mathrm{Y})$, and (iii) those with asymptomatic infection (A). The flow from one disease state to another is determined by a set of defined parameters. The population is divided into four sexual activity classes, defined according to the rates of sexual partner change of each group. ${ }^{42}$ Although infection with $T$ vaginalis induces humoral, cellular, and secretory immune responses there is no evidence for the development of long term immunity. We therefore assume that there is no immune class and that individuals return to the susceptible population following recovery from infection.

A description of the differential equations that define this model are available on request.

EPIDEMIOLOGICAL PARAMETER ESTIMATION

The major infection specific parameters are the duration of infection and its transmissibility. Although there are no recent community based studies that adequately describe the epidemiology of $T$ vaginalis infection, there were a number of surveys and experiments undertaken before the beginning of effective therapy which provide insights into the natural history of the disease. This information can assist in the estimation of parameters and state variables to be used in the modelling described below.

\section{Transmission probability}

There is some empirical evidence that permits rough insights about the transmission probability of $T$ vaginalis (table 2 ).

Male to female: Catteral ${ }^{43}{ }^{44}$ showed that between $85 \%$ and $100 \%$ of the female partners of a series of 120 men identified with $T$ vaginalis in two hospital clinics were also positive for $T$ vaginalis. Additionally, Whittington ${ }^{45}$ found that $10 / 15(66 \%)$ of the female contacts of male patients with $T$ vaginalis were infected.

Female to male: Studies have shown the number of infected male partners of infected women ranges from 4-80\%. Lancely and McEntegart ${ }^{46}$ quote a study by Karnacky undertaken in 1938 in which 38/150 (25.3\%) of the husbands of women with $T$ vaginalis were found to be infected, but figures of $41.9 \%, 60 \%$, and $80 \%$ were found when more careful investigation was undertaken. ${ }^{14} 4748$

The interpretation of such contact tracing data is fraught with difficulties. A first problem is to identify the source and direction of infec- tion. If a man is infected but his female partner is not, then presumably the man acquired infection first from someone else and failed to subsequently infect the traced partner. However, if both are infected, did the man infect the woman or vice versa? Or least likely, did both acquire infection from separate sources? From contact tracing data in the absence of excluding transmission in one direction we may be able to infer the upper but not the lower bounds for the transmission probabilities.

Upper bounds: It is reasonable to assume that all $T$ vaginalis infected individuals are infectious. If infection in women is indefinite (as appears to be the case), and assuming that the methods of diagnosis are sensitive, then the proportion of men's contacts that are infected is an upper bound of the transmission probability from men to women. The calculation of the transmission probability from women to men is more difficult since within a partnership a man can become infected, recover, and be reinfected. The proportion of male sex partners infected at a given time will be a function of the frequency of sex within the partnership, the transmission probability per sex act, and the duration of infection in men. The longer the duration of infection in men the lower the transmission probability per sex act that will generate a given proportion of infected men. Our standard model for STDs has a transmission probability per partnership, which is adequate for an initial investigation of $T$ vaginalis epidemiology, but a full understanding will require a more sophisticated appreciation of re-infection within partnerships. The transmission probability from women to men is probably higher than $50 \%$ over the duration of a long term partnership. However it might be a reasonable upper limit for short term partnerships, or per year within the partnership.

Lower bounds: Here, the direction of transmission is of paramount importance but there are no data to determine this. Women who are partners of infected men may have infected those men rather than vice versa. Clearly transmission is occurring but it is not possible to decide exactly where the lower bounds lie.

Another problem is that the means of diagnosing $T$ vaginalis was not consistent in these studies and the lower figures in the female to male studies may have resulted from the relative insensitivity of the diagnostic method

Table 2 Percentage of individuals infected by partners with known $T$ vaginalis infection

\begin{tabular}{|c|c|c|c|}
\hline Study & Year & Diagnostic method & $\begin{array}{l}\text { Number of partners } \\
\text { infected }(\%)\end{array}$ \\
\hline \multicolumn{4}{|l|}{ Female to male transmission } \\
\hline Drummond $^{47}$ & 1936 & Culture and microscopy of urethral swab, urine sediment, and prostatic fluid & $4 / 5(80 \%)$ \\
\hline Karnacky (in Lanceley) ${ }^{46}$ & 1938 & ? & $38 / 150(25.3 \%)$ \\
\hline Whittington ${ }^{11}$ & 1951 & Culture and microscopy of semen & $7 / 26(26.9 \%)$ \\
\hline Mascall $^{68}$ & 1954 & Unspecified & $6 / 150(4 \%)$ \\
\hline Burch $e t a l^{14}$ & 1959 & Culture of urethral swab or prostatic secretion & $13 / 31(41.9 \%)$ \\
\hline Watt and Jennison ${ }^{48}$ & 1960 & Culture of swab of preputial sac, urethra, and prostatic secretion & $18 / 30(60 \%)$ \\
\hline Rodin $e t a l^{69}$ & 1960 & Microscopy of urethral scrape, culture of urethral swab and urine & $11 / 38(29 \%)$ \\
\hline Weston and $\mathrm{Nicol}^{55}$ & 1963 & $\begin{array}{l}\text { Culture and microscopy of urethral discharge, scraping, urine sediment, } \\
\text { and prostatic fluid }\end{array}$ & $93 / 206(45.1 \%)$ \\
\hline Krieger et al ${ }^{8}$ & 1992 & Culture of swab of preputial sac (or coronal sulcus) and first void urine & $33 / 147(22.4 \%)$ \\
\hline \multicolumn{4}{|l|}{ Male to female transmission } \\
\hline Whittington $^{45}$ & 1957 & Microscopy and culture & $10 / 15(66.7 \%)$ \\
\hline Catterall and $\mathrm{Nicol}^{43}$ & 1960 & Microscopy and culture & $56 / 56(100 \%)$ \\
\hline Catterall $^{44}$ & 1960 & Culture and microscopy & $57 / 67(85.1 \%)$ \\
\hline
\end{tabular}


used. Culture of a urethral swab, prostatic fluid, and semen ${ }^{14} 478$ was probably the most sensitive combination (before the introduction of molecular techniques) but this was not always undertaken. A further problem is the small sample size of many studies, a problem particularly apparent when estimating the proportion of infections that remain asymptomatic and their duration.

\section{Asymptomatic infections}

The propensity to cause symptoms is an important feature of an organism as it determines the "immediate" morbidity and influences the frequency with which infected individuals will spontaneously seek medical attention. When considering their epidemiological relevance "symptomatic" infections could be defined as those which cause subjective awareness of illness in the infected individual, while "asymptomatic" infection is infection which leads to either no symptoms at all or to symptoms that are insufficiently troubling to lead the individual to seek care. The rate of asymptomatic disease may therefore be influenced by the prevailing expectations of health of the particular population.

Since most studies of $T$ vaginalis come from clinics, and are subject to important selection biases, it is not possible to determine the true proportion of patients with asymptomatic infection from these surveys. Nevertheless, they give some indication of the minimum proportion likely to occur in the broader community. Even in samples from the community the prevalent proportion of asymptomatic infections will only equal the proportion of incident infections that remain asymptomatic if symptomatic and asymptomatic infections have a similar duration. This is more likely to be true before the development of an effective treatment or in populations where symptoms go unrecognised.

Men: It was recognised in the pre-antibiotic era that the majority of men with $T$ vaginalis infection had mild or no symptoms. In a study of 926 male military recruits in the $1940 \mathrm{~s}, \mathrm{Feo}^{10}$ found that $15 \%$ were infected with $T$ vaginalis but that "all were relatively free of symptoms". Only one of seven infected male contacts of women involved in a $T$ vaginalis study in the United Kingdom admitted to symptoms when questioned $^{11}$ and of 63 male partners of infected women identified in a subsequent study by the same author, $12(20 \%)$ had no symptoms but the remaining 51 were said to have "very mild symptoms". ${ }^{45}$ Eight of 13 $(61.5 \%)$ infected male contacts of women identified in an STD clinic were asymptomatic. ${ }^{15}$ Studies before 1970 should be interpreted with caution as Chlamydia trachomatis diagnosis was not widely available and a proportion of symptoms may have been attributable to co-infection with $T$ vaginalis and $C$ trachomatis. A more recent study of 447 men attending an STD clinic in the United States found that $27 / 50(54 \%)$ men with $T$ vaginalis infection had symptoms, ${ }^{49}$ while in a high risk male population $24 / 49$ (49\%) had symptoms. ${ }^{25}$ It is reasonable to conclude that these latter two percentages are upper limits of symptomatic disease (table 1).

Women: Symptoms referable to infection with a specific STD may also be caused by non-transmissible pathogens or syndromes such as candidiasis or bacterial vaginosis, making the estimation of the proportion with symptomatic disease problematic. The only recent study to include a randomly selected community sample of women found that in 201 women living in rural areas of Papua New Guinea there was no statistically significant difference between women with $T$ vaginalis and those who were uninfected with respect to symptoms. ${ }^{37}$ Similar results were found in a survey of STD clinic patients in the United States. ${ }^{50}$ In a study of women attending a naval obstetric and gynaecology clinic Peterson ${ }^{9}$ found that only $36 \%$ had symptoms compatible with $T$ vaginalis infection. $\mathrm{Feo}^{51}$ found $13 / 24(54.2 \%)$ postmenopausal women with $T$ vaginalis to be symptomatic, while Wisdom and Dunlop found that $71.7 \%$ of female STD clinic attendees with $T$ vaginalis were symptomatic. ${ }^{15}$ A community based study of Aboriginal women in northern Australia showed that approximately $10 \%$ of women with $T$ vaginalis had reported symptoms at the time of diagnosis ${ }^{52}$ and in a Ugandan study only $19 \%$ of women with $T$ vaginalis or bacterial vaginosis reported symptoms in the previous 6 months. ${ }^{53}$

Because of the potential biases associated with the data presented, which are likely to lead to an overestimation of the proportion with symptoms, we have assigned the average proportion of symptomatic women with $T$ vaginalis infection as 0.4 and of men as 0.5 .

It is unknown if symptomatic disease has a different coefficient of transmission from symptomatic disease and for simplicity we make the assumption that the two are identical.

\section{Duration of infectiousness}

The duration of infectiousness (D) is also very difficult to determine.

Men: One survey suggests that in industrialised settings the duration of symptoms in men before they seek treatment is short (median of less than 1 day $)^{49}$ but a study in Zimbabwe showed that $78 \%$ of men with urethral trichomoniasis had symptoms present for more than 4 weeks. ${ }^{54}$ The studies from the pre-antibiotic era demonstrate that the duration may be longer but the evidence is conflicting and plagued by incomplete data, differing diagnostic criteria, and inconsistent protocols. Inoculation experiments in three volunteers, carried out in the 1950s, found the parasite for 4, 44, and 94 days respectively. ${ }^{46}$ A study of 19 untreated men who were partners of known infected women found that $T$ vaginalis could be identified for up to 101 days before treatment was given. Only five of the $19(26.3 \%)$ were seen to spontaneously resolve within 2 weeks. ${ }^{45}$ Weston and $\mathrm{Nicol}^{55}$ found that 10/38 (26.3\%) men with $T$ vaginalis infection spontaneously cleared the organism within 2 weeks of the presumed exposure, but overall there was a mean 
duration of at least 35 days (three patients had infection of greater than 84 days).

It is logical to conclude that patients who are aware of symptoms (and of their significance and have access to medical services) will have a shorter duration of infection than patients without symptoms. Only screening and contact tracing will identify asymptomatic individuals who will remain infected until natural recovery occurs. Unfortunately, there are few data to help estimate these respective values. Assuming that prolonged infection is the norm in the untreated individual but that spontaneous resolution occurs, we assigned a 120 day average duration of infection in men.

Women: Before metronidazole, treatment was of limited efficacy and many authors considered the disease to be of indefinite duration in women. ${ }^{56}$ This is supported indirectly by the observation of higher prevalence in older age groups in two surveys. ${ }^{14} 16$ An age structured survey of STD prevalence in Aboriginal women in northern Australia ${ }^{38}$ demonstrated that unlike $N$ gonorrhoeae and $C$ trachomatis where prevalence decreases with age, the prevalence of $T$ vaginalis increases with age, reaching $40 \%$ in the older than 40 years age group. These data demonstrate that there are important differences in the dynamics of infection between $T$ vaginalis and the other two STDs. As the rates of partner change and sexual mixing patterns are properties of the behaviour of the host population that are independent of the three infections, it must be differences in the duration of infectiousness or the coefficient of transmission that are responsible for the discrepant prevalences. We believe that an extremely long duration of infectiousness best explains such a high prevalence of $T$ vaginalis in the older age groups.

Model uncertainty and sensitivity analysis was investigated using Latin hypercube sampling (LHS) and a description of this work is available on request. ${ }^{57-59}$

TREATMENT EFFECTS

Efficacy of treatment

A single dose of a nitroimidazole (for example, metronidazole) results in cure rates above $90 \%{ }^{60}$; however, for the purposes of the model we have assumed that cure rates are $100 \%$.

"Syndromic management" versus screening

Syndromic management is the practice of treating individuals with a specific constellation of symptoms and signs according to a set protocol, without the need for a definitive laboratory diagnosis. The utility of this approach is that it is cheap, requires no laboratory services, and results in the immediate treatment of infected individuals. Its fundamental failing is that it does not deal with the majority of the infected population who are asymptomatically infected and who are only identified through screening (which identifies both asymptomatic and symptomatic individuals). In addition, symptomatic $T$ vaginalis infection is usually manifest as vaginal discharge or itch and the performance of syndromic management protocols in this context have been questioned. ${ }^{61}$
"Serial" versus "constant" screening

In some areas of high prevalence there may be considerable opportunity for individuals to use health services (for example, in urban settings in developed countries) while in others the health services may be rudimentary (for example, many developing countries). In the former group, the ready availability of appropriate testing, treatment, and counselling may result in the provision of what we have called "constant" screening, in which a set fraction of the population is screened over a unit time. The magnitude of this fraction will be determined by a number of factors - for example, the health seeking behaviour of the population, the acceptability of the services, and the effectiveness of their promotion.

The effect of treatment on the endemic prevalence of disease was simulated by altering the modelled fraction of infected individuals treated. If we consider the process of case finding and administering appropriate drugs, then the rate at which people are screened and treated, $\phi$, over time will lead to a fraction treated, $\mathrm{F}$, over a given period, t. Thus, $\mathrm{F}=1-$ $\mathrm{e}^{-\phi \mathrm{t} .}{ }^{62}$ Over a year the rate of treatment required to reach this fraction, $F$, is given by $\phi=-\ln (1-$ F). To translate screening and treatment into a rate of recovery of those infected this rate was calculated from the fraction of cases that would be treated per year in the absence of spontaneous recovery. Alternatively, the effect of "serial" screening on treatment was simulated by removing a proportion of individuals at one time point from the infected class and placing them in the susceptible class. This process was repeated at intervals of 6 months, 1, 2, and 5 years.

Syndromic management was simulated by adjusting the recovery rates (or by removal from the infected class for "serial" treatment) of those with symptomatic disease. Screening or mass presumptive antibiotic administration was simulated by "treating" an identical fraction within both the symptomatic and asymptomatic groups. Treatment of infected partners was not included in either of the treatment simulations.

The mean parameter values obtained in the LHS simulations which produced a prevalence of female infection of $0.30-0.35$ were used in the treatment simulations (table 3 ).

\section{Results}

On the basis of community studies in subSaharan Africa we chose to view a third of sexually active women infected to be a "reasonable" estimate of the prevalence of infection in the communities of interest. We then used this as a starting point (with a little leeway-that is, $30-35 \%$ prevalence) in uncertainty analysis to indicate the combinations of parameter values which could generate such a prevalence (table 3 ). The parameter values that produce a prevalence of $0.30-0.35$ are described using measures of central tendency and variation in table 3 . Noteworthy are the high recovery rates for men and the low rates for women indicating that the estimates derived 
Table 3 Descriptive statistics of output and input parameters for female prevalence of 0.30-0.35

\begin{tabular}{|c|c|c|c|c|c|c|c|c|c|c|}
\hline & $\begin{array}{l}\text { Total } \\
\text { prevalence }\end{array}$ & $\begin{array}{l}\text { Male } \\
\text { prevalence }\end{array}$ & $\begin{array}{l}\text { Female } \\
\text { prevalence }\end{array}$ & $\begin{array}{l}\text { Mean rate of } \\
\text { partner change }\end{array}$ & $\varepsilon$ & $\beta_{f m}$ & $\beta_{m f}$ & $\begin{array}{l}\text { Male recovery } \\
\text { rate (per year) }\end{array}$ & $\begin{array}{l}\text { Female recovery } \\
\text { rate (per year) }\end{array}$ & $\begin{array}{l}\text { Duration in sexually } \\
\text { active class (years) }\end{array}$ \\
\hline Minimum & 0.160 & 0.012 & 0.300 & 1.000 & 0.000 & 0.040 & 0.502 & 0.501 & 0.046 & 5.127 \\
\hline Maximum & 0.406 & 0.492 & 0.350 & 4.984 & 0.992 & 0.797 & 0.997 & 47.603 & 1.935 & 29.798 \\
\hline Mean & 0.232 & 0.137 & 0.326 & 2.279 & 0.354 & 0.346 & 0.709 & 3.054 & 0.296 & 15.959 \\
\hline Median & 0.222 & 0.118 & 0.326 & 1.973 & 0.267 & 0.310 & 0.697 & 1.364 & 0.146 & 15.190 \\
\hline Variance & 0.002 & 0.008 & 0.000 & 1.067 & 0.089 & 0.048 & 0.020 & 29.038 & 0.124 & 51.949 \\
\hline
\end{tabular}

$\varepsilon$ is the determinant of mixing; $\varepsilon=1$ : fully assortative mixing; $\varepsilon=0$ : random mixing. $\beta_{\mathrm{fm}}+=$ coefficient of transmission from female to male. $\beta_{\mathrm{mf}}=$ coefficient of transmission from male to female.

from the literature are consistent with observed prevalences.

In our model we have simulated the effects of "syndromic management" and screening, applied in a "serial" and "constant" programme (fig 1). It is not surprising, given the proportion of asymptomatic disease, that even very high levels of syndromic management coverage (which are almost certainly unobtainable in the field) result in only modest reductions in the endemic prevalence of infection. On the other hand, modest (and presumably achievable) levels of coverage of screening lead to significant reductions in the prevalence of $T$ vaginalis, with "constant" screening (facilitated by a good health infrastructure) being more effective than "serial" screening. We have assumed that $50 \%$ of disease is asymptomatic for the model but we believe that this is a conservative estimate (tending to underestimate) - the true benefit of syndromic management is therefore likely to be less than the simulations suggest.

The effect of different coverage rates and screening intervals on the endemic prevalence is shown in Figure 2A and B. Screening at 5 yearly intervals has minimal effect on prevalence regardless of coverage, while 6 monthly screening is highly effective (but probably impractical). An interval of 12 months may be achievable in some healthcare systems and will result in substantial reductions in prevalence of disease.

Assuming 50\% coverage of the population occurring at yearly intervals, we simulated the effect of screening either both sexes together or

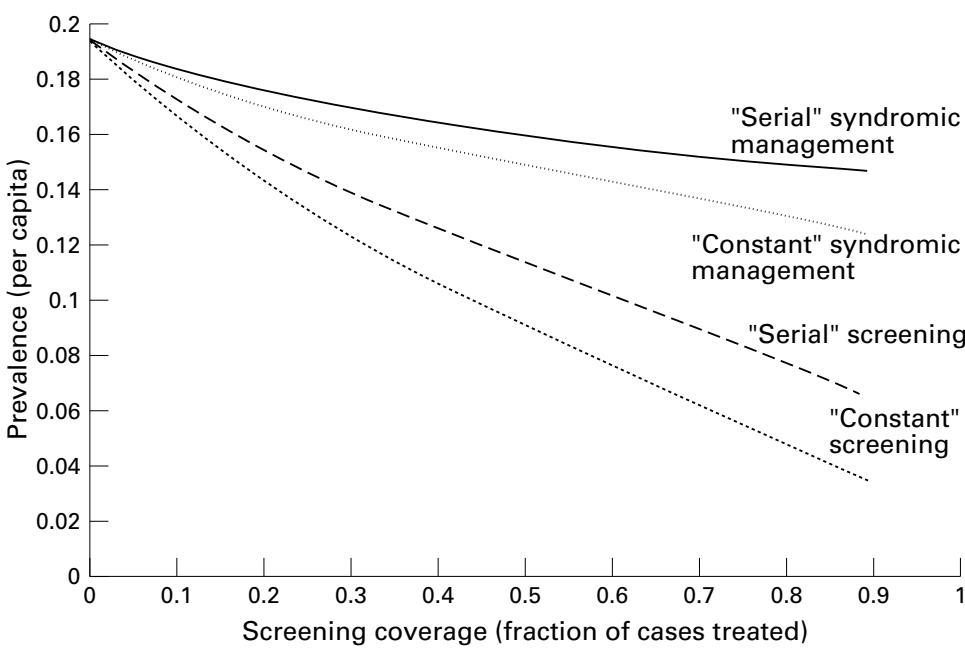

Figure 1 The effect of different levels of coverage (fraction of infections treated) on the equilibrium prevalence of infection for "serial" and "constant" syndromic management (that is, treatment of symptomatic cases only) compared with serial and constant screening of mass antibiotic administration for the whole population. The mean parameters from table 3 were used as a baseline. one sex alone (fig 3). Screening men alone has minimal impact on prevalence, and although the nadir of prevalence is lower in screening of both sexes, there was only a modest difference in the total prevalence at the due time of the next screen if women only were screened.

\section{Discussion}

The absence of prospective data in well defined populations means that the true dynamics of $T$ vaginalis infection are unknown. Nevertheless, the most striking feature of the epidemiology is the consistently high prevalence found in women in developing and disadvantaged populations.

The effects of $T$ vaginalis on pregnancy outcome have been known for many years ${ }^{20}$ and are now receiving increased attention. ${ }^{4}$ It is possible that treatment of women with $T$ vaginalis in pregnancy will reduce the incidence of premature rupture of membranes and premature labour, although one study has failed to show this. ${ }^{63}$ Of course, lowering the risk of infection in the first place through reductions in the community prevalence of the disease is a better long term option.

Although some authors consider the epidemiology of $T$ vaginalis to be similar to other bacterial STDs, ${ }^{6465}$ the few studies which look at age specific prevalence $e^{141638}$ demonstrate a continuous increase with age, a feature that is not common to $N$ gonorrhoeae or $C$ trachomatis. Targeting of particular age groups is sometimes suggested as a strategy for STD control but if $N$ gonorrhoeae or $C$ trachomatis are chosen as the marker diseases, older women infected with $T$ vaginalis will not be identified.

In addition, $T$ vaginalis almost always occurs at higher prevalence than the bacterial STDs in studies in disadvantaged communities. These observations can best be explained by postulating an extremely long duration of infectiousness, an assumption supported by the preantibiotic literature. In our model a duration of 3-5 years was needed in the female group to produce a prevalence of $35 \%$ in women. The duration in men is almost certainly shorter, as a result of the protective effects of non-specific urethral immunological defences, the physical clearing by the stream of urine and possibly the increased proportion of men with symptomatic disease which brings them to medical services. The relative rarity of $T$ vaginalis in developed country populations is likely to be due to the identification of $T$ vaginalis through Pap smears, antenatal care, and through the increased rate of health seeking behaviour (linked to adequate access to suitable services) experienced by individuals in these settings. 

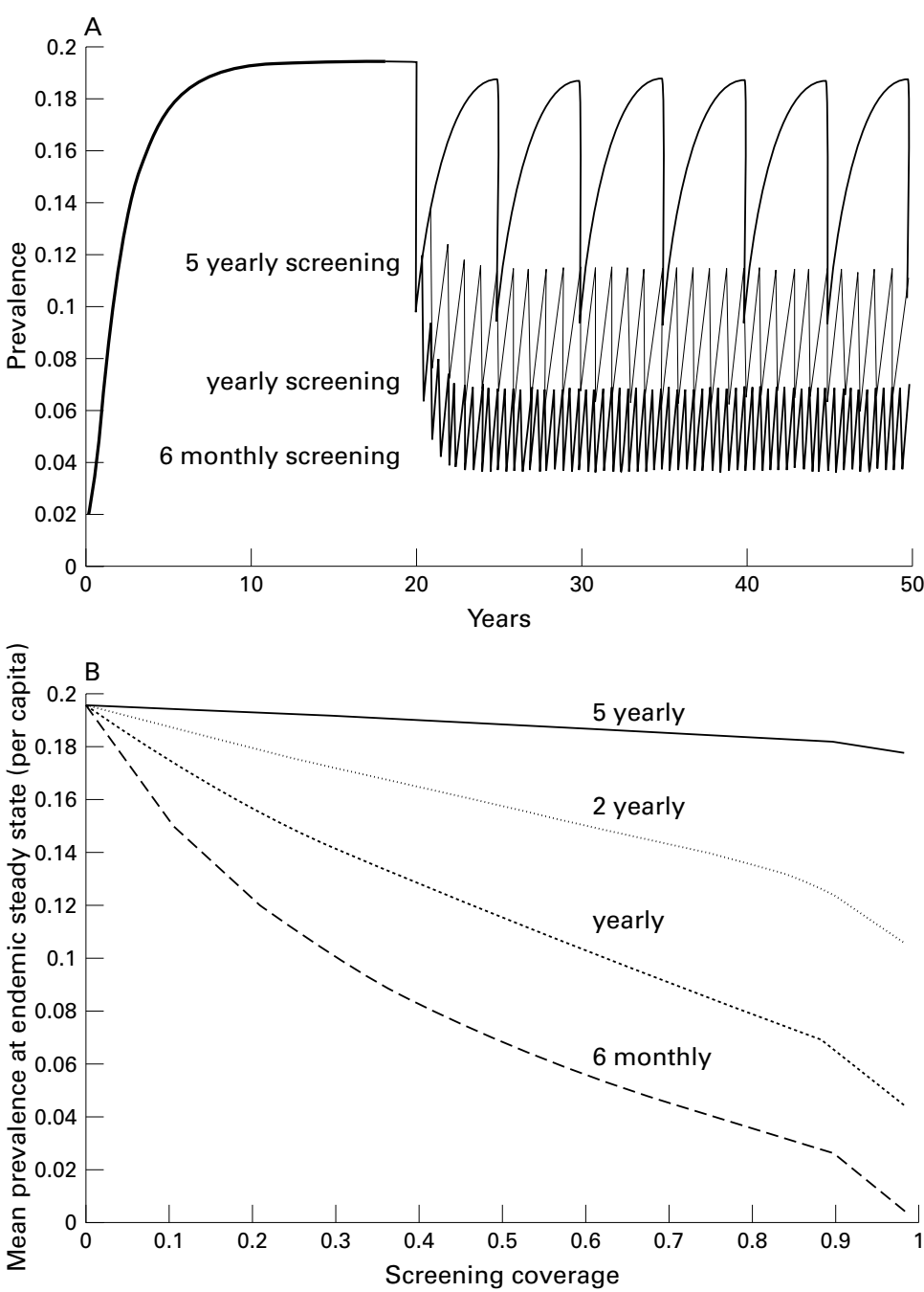

Figure 2 The impact of serial treatment on the prevalence of Trichomonas vaginalis starting at year 20 using mean parameters from table 3. (A) The impact through time of the frequency of treating a random sample of $50 \%$ of infections at different intervals. (B) The relation between the fraction of infections treated at each round (screening coverage) and the average steady state prevalence for treatment of infections at different intervals.

The widespread treatment of the syndrome of bacterial vaginosis with nitroimidazoles may also have had an important effect. In addition, there may be differences in the interaction of

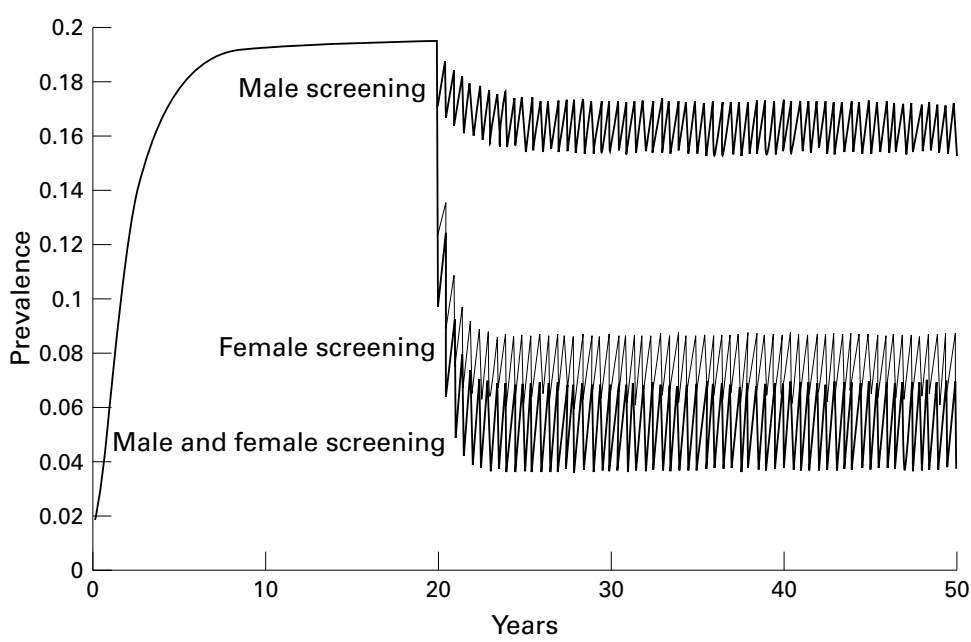

Figure 3 The impact of "serial" screening of one or both sexes at yearly intervals with a $50 \%$ coverage using mean parameters from table 3. sexual networks and sexual core groups between the two populations.

The fact that the epidemiology of $T$ vaginalis differs from the two major bacterial pathogens is important as it influences the approach that is required to design control strategies. The model we have described is a simple representation of the presumed dynamics of $T$ vaginalis infection. The uncertainty and sensitivity analyses show that there are a number of important gaps in our knowledge about the epidemiological parameters that constitute the model. Nevertheless, the model demonstrates a number of salient points: (i) the importance of the proportion of individuals with asymptomatic disease in influencing the success or otherwise of the syndromic approach to STD control. There is uncertainty about the fraction of infections that remain asymptomatic, but what is not in doubt is that asymptomatic infections are common and the greater the proportion of infections without symptoms or the less well recognised they are the less the impact of syndromic management. Without a general improvement in health care it is clear that any programme for $T$ vaginalis that relies solely upon this strategy will be unlikely to achieve a sustained decrease in the total prevalence of disease regardless of the degree of patient coverage; (ii) the frequency of screening will determine the ultimate endemic prevalence; (iii) the presumed asymmetry of the recovery rates for male and females means that treatment of women is likely to have a greater effect on prevalence than treatment of men. The treatment of both sexes rather than just women will result in only a small decrement in the prevalence. This result depends upon the duration of infectiousness being lower for men than women, which seems to be a realistic assumption. Its consequence is that energies should be directed more to female screening than to male screening, which probably occurs already in reality as women tend to use health services on average more often than men in most areas where $T$ vaginalis in endemic; (iv) "constant" screening (that is, the provision of good primary healthcare STD services with good population outreach) is more effective than "serial" screening, because for a given coverage the fraction of infections actually treated is greater. In effect we are comparing treating a given percentage of infections at one point in time with treating a fraction of all cases. Unfortunately the impoverishment of most endemic areas means that such services are uncommon. Regular "serial" screening may be more achievable in most settings.

In presenting our results we have chosen to use one set of parameter values, but the impact of varying parameters on interventions is easily summarised. To generate a particular endemic prevalence of infection before an intervention there is a trade off between the duration of infectiousness, the contact rate, and the transmission probability. A shorter duration of infectiousness implies a higher contact rate or a higher transmission probability. The higher the latter two values the more rapidly infection can bounce back following around of treatment. A 
shorter duration of infectiousness would reduce the impact of both continuous and serial interventions.

An important assumption in this model is that identification and treatment of disease does not lead to any change in sexual behaviour - that is, reduction in number of sexual partners or use of condoms. It is likely that properly conducted screening activities which are linked to counselling services will have some effect upon behaviour and would result in a larger reduction in prevalence than is predicted from these simulations.

The advent of non-invasive testing for STDs using amplification technology (for example, from first void urine samples in men and self administered swabs in women) should facilitate prospective, age structured epidemiological studies of $T$ vaginalis in the community, which will be useful in helping to shape future control programmes. Diagnostic tests will probably remain expensive and the hyperendemicity of the disease in many populations raises the possibility of instituting widespread treatment of all women regardless of symptoms, signs, or laboratory investigations. In some areas the positive predictive value for $T$ vaginalis infection of the marker of residence in the population will equal the prevalence of the disease - that is, 35-50\%, a level that many investigators would be happy to achieve for a sophisticated diagnostic test for other pathogens of lower prevalence. Recommendations for single dose nitroimidazole therapy for all women who have been sexually active at any stage in their life may be appropriate and could be instituted at family planning clinics and other primary healthcare facilities in areas of known high endemic prevalence.

Infection with $T$ vaginalis has been largely ignored by most health professionals since its discovery over 160 years ago but its relative importance is now beginning to be recognised. Control of the disease is dependent on a cheap, safe, and well tolerated antibiotic and should not be ignored

Contributors: The mathematical model was developed and parameterised in collaboration between the authors. FB carried out the literature review; GG coded the model solution and the sensitivity analysis routine; and FB carried out and analysed the simulations. Both authors drafted the manuscript.

The authors thank Neil Ferguson, Azra Ghani, and Andrew Roddam for helpful comments. GPG is a Royal Society University Research Fellow. FJB was supported by a Wellcome Trust Travelling Fellowship.

The appendix to this paper is available on request from the journal office.

1 World Health Organization. Global prevalence and incidence of selected curable sexually transmitted diseases: overview and estiWHO, 1995.

2 Petrin D, Delgaty K, Bhatt R, et al. Clinical and microbiological aspects of Trichomonas vaginalis. Clin Microbiol Rev 1998;11:300-17.

3 Heine P, McGregor JA. Trichomonas vaginalis: a reemerging pathogen. Clin Obstet Gynecol 1993;36:137-44.

4 Cotch MF, Pastorek JG, 2nd, Nugent RP, et al. Trichomonas vaginalis associated with low birth weight and preterm delivery. The Vaginal Infections and Prematurity Study Group. Sex Transm Dis 1997;24:353-60.

5 ter Meulen J, Mgaya HN, Chang-Claude J, et al. Risk factors for HIV infection in gynaecological inpatients in Dar es Salaam, Tanzania, 1988-1990. East Afr Med f 1992;69: 688-92.

6 Laga M, Manoka A, Kivuvu M, et al. Non-ulcerative sexually transmitted diseases as risk factors for HIV-1 transmission in women: results from a cohort study. AIDS 1993;7:95-102
7 Ghys PD, Diallo MO, Ettiegne-Traore V, et al. Genital ulcers associated with human immunodeficiency virusulcers associated with human immunodeficiency virus-
related immunosuppression in female sex workers in Abidjan, Ivory Coast. F Infect Dis 1995;172:1371-4.

8 Sorvillo F, Kerndt P. Trichomonas vaginalis and amplification of HIV-1 transmission [letter]. Lancet 1998;351:2134.

9 Peterson P. Trichomonas vaginalis vaginitis. A comparative study of treatment and incidence. Am $\mathcal{F}$ Obstet Gyn 1938;35:1004-9.

10 Feo LG. The incidence and significance of Trichomonas vaginalis in the male. Am f Tropical Med 1943;24:195-8.

11 Whittington MJ. The occurrence of Trichomonas vaginalis in semen. F Obstet Gynaecol Brit Emp 1951;58:615-19.

12 Coutts WE, Vargas-Salazar R, Silva-Inzunza E, et al. Trichomonas vaginalis infection in the male. BMF 1955; ii: 885-89.

13 Buxton CL, Weinman D, Johnson C. Epidemiology of Trichomonas vaginalis vaginitis. Obstet Gynec 1958;12:699702

14 Burch TA, Rees CW, Reardon LV. Epidemiological studies on human trichomoniasis. Am F Trop Med Hyg 1959;8:31218

15 Wisdom AR, Dunlop EMC. Trichomoniasis. Study of the disease and its treatment. Br F Vener Dis 1965;41:90-6.

16 Zigas V. An evaluation of trichomoniasis in two ethnic groups in Papua New Guinea. Sex Transm Dis 1977;4:63-5.

17 Tapsall JW, Puglisi J, Smith DD. Trichomonas vaginalis infections in Sydney: laboratory diagnosis and prevalence. Med F Aust 1979;1:193-4.

18 Wilson A, Ackers JP. Urine culture for the detection of Trichomonas vaginalis in men. Brf Vener Dis 1980;56:46-8.

19 Mirza NB, Nsanze H, LJ DC, Piot P. Microbiology of vaginal discharge in Nairobi, Kenya. Br $\mathcal{F}$ Vener Dis 1983;59: $186-8$.

20 Hardy PH, Hardy JB, Nell EE, et al. Prevalence of six sexually transmitted disease agents arising in pregnant innercity adolescents and pregnancy outcome. Lancet 1984;2: 333-7.

21 Mabey DC, Lloyd-Evans NE, Conteh S, et al. Sexually transmitted diseases among randomly selected attenders at an antenatal clinic in The Gambia. Br F Vener Dis 1984;60: 331-6.

22 Wolner-Hanssen P, Kreiger JN, Stevens C, et al. Clinical manifestations of vaginal trichomoniasis. $\mathscr{F} A M A$ 1989;261: $571-6$.

23 O Farrell N, Hoosen AA, Kharsany AB, et al. Sexually transmitted pathogens in pregnant women in a rural South African community. Genitourin Med 1989;65:276-80.

24 Lefevre JC, Lepargneur JP, Bauriaud R, et al. Clinical and microbiologic features of urethritis in men in Toulouse, microbiologic features of urethritis in

25 Saxena SB, Jenkins RR. Prevalence of Trichomonas vaginalis in men at high risk for sexually transmitted diseases. Sex Transm Dis 1991;18:138-42.

26 Iyer SV, Deodhar L, Gogate A. Microbiological evaluation of female patients in STD clinics. Indian $f$ Med Res 1991;93:95-7.

27 Stefanik M, Rychna K, Valkoun A. Microbial causative agents of male urethritis. F Hyg Epidemiol Microbiol Immunol 1992;36:111-8

28 Krieger JN, Verdon M, Siegel N, et al. Risk assessment and laboratory diagnosis of trichomoniasis in men. F Infect Dis 1992;166:1362-6.

29 Anosike JC, Onwuliri CO, Inyang RE, et al. Trichomoniasis amongst students of a higher institution in Nigeria. Appl Parasitol 1993;34:19-25.

30 Cronje HS, Joubert G, Muir A, et al. Prevalence of vaginitis, syphilis and HIV infection in women in the Orange Free syphilis and HIV infection in wom

31 Borchardt KA, al-Haraci S, Maida N. Prevalence of Trichomonas vaginalis in a male sexually transmitted disease clinic population by interview, wet mount microscopy, and the InPouch TV test. Genitourin Med 1995;71: 405-6.

32 Tabrizi SN, Paterson B, Fairley CK, et al. A selfadministered technique for the detection of sexually transmitted diseases in remote communities. F Infect Dis 1997;176:289-92.

33 Heine RP, Wiesenfeld HC, Sweet RL, et al. Polymerase chain reaction analysis of distal vaginal specimens: a less invasive strategy for detection of Trichomonas vaginalis. Clin Infect Dis 1997;24:985-7.

34 Klouman E, Masenga EJ, Klepp KI, et al. HIV and reproductive tract infections in a total village population in rural Kilimanjaro, Tanzania: women at increased risk. 7 Acquir Immune Defic Syndr Hum Retrovirol 1997;14:163-8.

35 Waghorn DJ, Tucker PK, Chia Y, et al. Collaborative approach to improve the detection and management of trichomoniasis in a low prevalence district. Int $\mathcal{F}$ STD AIDS 1998;9:164-7

36 el Seoud SF, Abbas MM, Habib FS. Study of trichomoniais among Egyptian male patients. F Egypt Soc Parasitol 1998;28:263-70

37 Passey M, Mgone CS, Lupiwa S, et al. Community based study of sexually transmitted diseases in rural women in the highlands of Papua New Guinea: prevalence and risk factors. Sex Transm Inf 1998;74:120-7.

38 Bowden FJ, Paterson BA, Mein J, et al. Estimating the prevalence of Trichomonas vaginalis, Chlamydia trachomatis, and Neisseria gonorrhoeae in indigenous women in Northern Australia. Sex Transm Inf 1999;75:431-4.

39 Ipsen J, Feigl P. A biomathematical model for prevalence of Trichomonas vaginalis. Am f Epidemiol 1970;91:175-84. 
40 Hethcote HW, Yorke JA. Gonorrhea transmission dynamics and control. Berlin: Springer-Verlag, 1984

41 Garnett GP, Mmertz KJ, Finelli I, et al. The transmission dynamics of gonorrhoea: modelling the reported behaviour of infected patients from Newark, New Jersey. Philos Trans $R$ Soc Lond B Biol Sci 1999;354:787-97.

42 Garnett GP, Anderson RM. Contact tracing and estimation of sexual mixing patterns. The epidemiology of gonococcal infections. Sex Transm Dis 1993;20:181-91.

43 Catterall RD, Nicol CS. Is trichomonal infestation a venereal disease? BMf 1960;i:1177-9.

44 Catterall RD. Diagnosis and treatment of trichomonal urethritis in men. BMF 1960;i:113-15.

45 Whitington MJ. Epidemiology of infections with Trichomonas vaginalis in the light of improved diagnostic methods. Br f Vener Dis 1957;33:80-91.

46 Lanceley F, McEntegart MG. Trichomonas vaginalis in the male. The experimental infection of a few volunteers. Lancet 1953;i:668-71.

47 Drummond AC. Trichomonas infestation of the prostate gland. Am F Surg 1936;31:98-103.

48 Watt L, Jennison RF. Incidence of Trichomonas vaginalis in marital partners. Br f Vener Dis 1960;36:163-6.

49 Krieger JN, Verdon M, Siegel N, et al. Natural history of Krieger JN, Verdon M, Siegel N, et al. Natural history of
urogenital trichomoniasis in men. $\mathcal{F}$ Urol 1993;149:1455-8.

50 Madico G, Quinn TC, Rompalo A, et al. Diagnosis of trichomonas vaginalis infection by PCR using vaginal swab samples. F Clin Microbiol 1998;36:3205-10.

51 Feo LG. Trichomonas vaginalis infection in postmenopausal women. Am f Obstet Gynecol 1956;72:1335-9.

52 Paterson BA, Tabrizi SN, Garland SM, et al. The tampon test for trichomoniasis: a comparison between conventional methods and a polymerase chain reaction for Trichomonas vaginalis in women. Sex Transm Inf 1998;74:136-9.

53 Paxton LA, Kiwanuka N, Nalugoda F, et al. Community based study of treatment seeking among subjects with symptoms of sexually transmitted disease in rural Uganda. BMF 1998;317:1630-1.

54 Latif AS, Mason PR, Marowa E. Urethral trichomoniasis in men. Sex Transm Dis 1987;14:9-11.

55 Weston TET, Nicol CS. Natural history of trichomonal infection in males. Br f Vener Dis 1963;39:251-7.

56 Wilcox RR. Epidemiological aspects of trichomoniasis. $\mathrm{Br} \mathcal{F}$ Vener Dis 1960;36:167-74
57 Blower SM, Dowlatabadi H. Sensitivity and uncertainty analysis of complex models of disease transmission: an HIV model, as an example. Int Stat Rev 1994;62:229-43.

58 Chan MS. The consequences of uncertainty for the prediction of the effects of schistosomiasis control programmes. Epidemiol Infect 1996;117:537-50.

59 JMP statistics [program]. 3.2.1 version: SAS Institute, 1996.

60 Gulmezoglu AM, Garner P. Trichomoniasis treatment in women: a systematic review. Trop Med Int Health 1998;3: 553-8.

61 Passey M, Mgone CS, Lupiwa S, et al. Screening for sexually transmitted diseases in rural women in Papua New Guinea: are WHO therapeutic algorithms appropriate for case detection? Bull World Health Organ 1998;76:401-11.

62 Blower SN, Small PM, Hopewell PC. Control strategies for tuberculosis epidemics:new models for old problems. Science 1996;273:497-500.

63 Carey JC, Klebanoff MA, Hauth JC, et al. Metronidazole to prevent preterm delivery in pregnant women with asymptomatic bacterial vaginosis. National Institute of Child Health and Human Development Network of MaternalFetal Medicine Units [see comments]. N Engl f Med 2000; 342:534-40

64 Krieger JN. Trichomoniasis in men: old issues and new data. Sex Transm Dis 1995;22:83-96.

65 Krieger JN, Alderete JF. Trichomonas vaginalis and trichomoniasis. In: Holmes KK SP, Mardh PA, Lemon SA, Stamm WE, Piot P, Wasserheit JN, eds. Sexually transmitted diseases. New York: McGraw-Hill, 1999.

66 DeHovitz JA, Kelly P, Feldman J, et al. Sexually transmitted diseases, sexual behavior, and cocaine use in inner-city women. Am $\mathcal{F}$ Epidemiol 1994;140:1125-34.

67 Sorvillo F, Kovacs A, Kerndt P, et al. Risk factors for trichomoniasis among women with human immunodeficiency virus (HIV) infection at a public clinic in Los Angeles County, California: implications for HIV prevention. Am $\mathcal{F}$ Trop Med Hyg 1998;58:495-500.

68 Mascall N. Some reflections on the Trichomonas vaginalis. Brf Vener Dis 1954;30:156-62.

69 Rodin P, King AJ, Nicol CS, et al. Flagyl in the treatment of trichomoniasis. Br F Vener Dis 1960;36:147-51. 